Original Research Article

\title{
To study the prescription pattern of antibiotics in medicine intensive care unit at tertiary care hospital
}

\author{
Imran B. Naikwadi ${ }^{1}$, Mirza Shiraz Baig ${ }^{1 *}$, Meenakshi Bhattacharya ${ }^{2}$
}

\begin{abstract}
${ }^{1}$ Department of Pharmacology,
${ }^{2}$ Department of Medicine, Government Medical College, Aurangabad, Maharashtra, India
\end{abstract}

Received: 30 January 2019

Revised: 10 March 2019

Accepted: 11 March 2019

\section{*Correspondence to:}

Dr. Mirza Shiraz Baig,

Email: shirazdoctor@yahoo.com

Copyright: (C) the author(s), publisher and licensee Medip Academy. This is an openaccess article distributed under the terms of the Creative Commons Attribution NonCommercial License, which permits unrestricted noncommercial use, distribution, and reproduction in any medium, provided the original work is properly cited.

\begin{abstract}
Background: Drug utilization studies are crucial and create a positive awareness about proper use of drugs. Analysing the pattern of prescriptions is important in the settings of intensive care units where patients receive multiple antibiotics. The objective of this study was to analyse the use of antibiotics in a Medicine Intensive Care Unit (MICU) of Government Medical College and Hospital, Aurangabad, Maharashtra, India, a tertiary health care centre.

Methods: Total 988 number of patients admitted in MICU from January 2017 to June 2018 were enrolled in the study and fulfilling inclusion criteria. Demographic details, disease state and prescription of antibiotic was recorded.

Results: Out of 988, $\mathrm{n}=700$ patients received antibiotics. Most common diseases for which patients were admitted in MICU included OP poisoning $(24.86 \%)$, snake bite (15.14\%), bilateral pneumonitis (12.71\%), HELLP syndrome $(12.14 \%)$, and the least common conditions were chronic obstructive pulmonary disease (COPD), meningitis, sepsis with multiple organ dysfunction syndrome (MODS), Guillen barre syndrome (GBS), lung abscess etc., Most common single antibiotic used in the studied cases was ceftriaxone $(21.42 \%)$ followed by either alone or in combination piperacillin and tazobactam (12.04\%), metronidazole $(11.85 \%)$ etc.

Conclusions: Total 700 patients received systemic antibiotics in present study bringing the incidence of systemic antibiotics use in MICU to be $70.85 \%$. Ceftriaxone and combination of piperacillin and tazobactam are most commonly used antibiotics in MICU of the hospital. All patients admitted in this MICU received antibiotics as per the standard protocols of the hospital.
\end{abstract}

Keywords: Antibiotics, Drug utilization, MICU

\section{INTRODUCTION}

Drug utilization studies are crucial since they identify the problems and provide feedback to prescribers. The obtained information can provide insights of drug use, drug prescribing pattern, quality of use, and therapeutic outcomes. ${ }^{1}$ Irrational, prolonged and improper use of antibiotics is responsible for menace of increasing drug resistance amongst the infecting organisms. Appropriate use of antibiotics has reduced the morbidity and mortality due to infections to a significant level. ${ }^{2}$ Analysing the pattern of prescriptions becomes all the more important in the settings of Medicine Intensive Care Unit (MICU) as in this setting patients are critically ill and are known to be receiving multiple antibiotics. ${ }^{3}$ Not only the cost of hospitalization is high in MICU but also the cost of medications is also considerably high. Most of the patients in MICU often suffer from severe illnesses, multiple organs dysfunction and coexisting medical disorders. ${ }^{4}$ In such situation, prescribing multiple drugs becomes. ${ }^{5} \mathrm{~A}$ major portion of drugs prescribed to patients admitted in MICU consist of antibiotics. The present scenario of 
Government hospitals and public hospitals which caters to ever increasing burden of patients and where effectiveness cost is an important consideration while managing seriously ill patients admitted in MICU makes drug utilization studies significant for framing proper protocols of antibiotic use in hospitals. Management in MICU by physicians with varying levels of critical care training is associated with major patient safety challenges and thus requires complex and urgent decision making considering all possible outcomes. ${ }^{6}$

Periodic evaluation of drug prescribing patterns in the MICU, therefore, becomes necessary for optimum use of health care delivery system, proper use of resources and prevention of emergence of multidrug resistance organisms. Identifying the antibiotics usage especially in MICU will provide insights into the strategies and policies in a respective tertiary care set up where the patients load in immense. The aim of present study was to analyse antibiotic prescribing pattern in MICU of a Tertiary Care Government Medical College and Hospital, Aurangabad, Maharashtra, India.

\section{Aims and objectives}

\section{Primary}

To study the prescription pattern of antibiotics in Medicine Intensive care unit (MICU).

\section{Secondary}

To identify the disease states and class of antibiotics commonly used in MICU and use of one or more than one antibiotic in MICU.

\section{METHODS}

Present study was prospective, observational, open label and descriptive clinical study where 988 patients admitted in MICU between January 2017 to June 2018.

\section{Inclusion criteria}

- Patients admitted in MICU,

- Patients or relatives willing to give informed consent.

\section{Exclusion criteria}

- Not willing to give informed consent,

- Not willing to give follow up if required,

- Incomplete data and patients who stayed for less than 24 hours.

\section{Procedure}

Subjects fulfilling the inclusion/exclusion criteria and giving a written informed consent were enrolled in the study. All the patients coming under the inclusion criteria were explained about the need for doing this study and their written informed consent was taken. The records of the patients were obtained from the case record form. Baseline demographic variables were recorded. The prescription data of all patients at admission into the MICU was noted with regards to antibiotic prescription and the class of antibiotics. The antibiotics prescription pattern was analyzed till the patient was discharged from MICU.

Graph Pad Prism Software Version 7 was used for statistical analysis. For qualitative data chi-square/fisher exact test was used and for quantitative data student unpaired t-test/test of difference between two means was used for intergroup and paired t-test/test of difference between two means was done for intragroup. For statistical purposes, $\mathrm{p}$ value less than 0.05 was taken as statistically significant.

\section{RESULTS}

A total of 988 patients aged 18 years and above and who were admitted in MICU for the treatment of various illnesses were reviewed over a period from January 2017 to June 2018. Out of the total 988 patients admitted in MICU, 700 patients received systemic antibiotics bringing the incidence of systemic antibiotics use in the intensive care units to be $70.85 \%$ (Table 1 ).

Table 1: Antibiotics used in MICU.

\begin{tabular}{|lll|}
\hline Antibiotics in MICU & No. of patients & $\%$ \\
\hline Used & 700 & $70.85 \%$ \\
\hline Not used & 288 & $29.15 \%$ \\
\hline Total & 988 & $100 \%$ \\
\hline
\end{tabular}

The analysis of gender distribution of the studied cases showed that out of 700 patients, there were $423(60.43 \%)$ males and 277 (39.57\%) females (Table 2). There was a male preponderance in studied cases with a $\mathrm{M}: \mathrm{F}$ ratio of $1: 0.65$.

Table 2: Gender distribution of the studied cases.

\begin{tabular}{|lll|}
\hline Gender & No. of patients & $\%$ \\
\hline Males & 423 & $60.43 \%$ \\
\hline Females & 277 & $39.57 \%$ \\
\hline Total & 700 & $100 \%$ \\
\hline
\end{tabular}

Table 3: Age distribution of the studied cases.

\begin{tabular}{|lll|}
\hline Age groups & No. of patients & $\%$ \\
\hline Up to 20 & 54 & $7.71 \%$ \\
\hline $21-30$ & 277 & $39.57 \%$ \\
\hline $31-40$ & 195 & $27.86 \%$ \\
\hline $41-50$ & 27 & $3.86 \%$ \\
\hline $51-60$ & 58 & $8.29 \%$ \\
\hline Above 60 & 89 & $12.71 \%$ \\
\hline Total & 700 & $100 \%$ \\
\hline \multicolumn{2}{l}{ Mean age of the studied cases=34.16 $=14.13$ years } \\
\hline
\end{tabular}


The analysis of the age groups of the patients showed that the most common age group of the patient was 21-30 years (39.57\%) followed by 31-40 years $(27.86 \%)$, and above 60 years $(12.71 \%)$ (Table 3$)$. Least common age group was found to be $41-50$ years in which there were only 27 $(3.86 \%)$ patients. The mean age of the patients was found to be 34.16 with standard deviation of 14.13 years. The most common age group in male patients was found to be
21-30 years $(25.43 \%)$ and $31-40$ years $(17.14 \%)$ similarly in females the most common age group was found to be 21 30 years $(14.14 \%)$ (Table 4$)$. The mean age of the male patients was found to be $33.99 \pm 13.10$ while the mean age of females was found to be $35.13 \pm 15.17$. The difference was not found to be statistically significant $(\mathrm{P}=0.29)$ and age groups of men and women were found to be comparable (Table 5).

Table 4: Gender wise distribution of age groups.

\begin{tabular}{|lllllll|}
\hline Age Groups & Males & & Females & & Total \\
\hline Up to 20 & No. of cases & Percentage & No. of cases & Percentage & No. of cases & Percentage \\
\hline $21-30$ & 35 & $5.00 \%$ & 19 & $2.71 \%$ & 54 & $7.71 \%$ \\
\hline $31-40$ & 178 & $25.43 \%$ & 99 & $14.14 \%$ & 277 & $39.57 \%$ \\
\hline $41-50$ & 120 & $17.14 \%$ & 75 & $10.71 \%$ & 195 & $27.86 \%$ \\
\hline $51-60$ & 12 & $1.71 \%$ & 15 & $2.14 \%$ & 27 & $3.86 \%$ \\
\hline Above 60 years & 33 & $4.71 \%$ & 25 & $3.57 \%$ & 58 & $8.29 \%$ \\
\hline Total & 45 & $6.43 \%$ & 44 & $6.29 \%$ & 89 & $12.71 \%$ \\
\hline
\end{tabular}

Table 5: Comparison of gender wise age distribution.

\begin{tabular}{|c|c|c|c|}
\hline Gender & Mean age & SD & Test of significance \\
\hline Males & 33.99 & 13.10 & \multirow{2}{*}{$\begin{array}{l}P=0.29 \text {, Statistically } \\
\text { not significant }\end{array}$} \\
\hline Females & 35.13 & 15.17 & \\
\hline
\end{tabular}

The records of the patients were analyzed for presence of co-morbidity and systemic illnesses.

It was found that out of 700 patients, diabetes was present in $72(10.29 \%)$ patients whereas hypertension was present in $102(14.57 \%)$ cases. $98(14 \%)$ patients were having diabetes as well as hypertension whereas in 428 (61.14\%) there was no systemic illness prior to admission in the hospital (Table 6).

Table 6: Co-morbidities in the studied cases.

\begin{tabular}{|lll|}
\hline Presence of co-morbidities & No. of patients & $\%$ \\
\hline Diabetes & 72 & 10.29 \\
\hline Hypertension & 102 & 14.57 \\
\hline Diabetes and hypertension & 98 & 14.00 \\
\hline No co-morbidity & 428 & 61.14 \\
\hline Total & 700 & 100 \\
\hline
\end{tabular}

Various pathologies for which the cases were admitted in MICU were analyzed and incidence of various diseases were studied.

The analysis of the patients on the basis of presence of etiology showed that the most common disease for which patients were admitted in MICU included organophosphorus poisoning $(24.86 \%)$ followed by snake bite (15.14\%), bilateral pneumonitis $(12.71 \%)$ and HELLP syndrome (12.14\%). The least common pathologies included alcoholic liver disease $(1.57 \%)$, chronic kidney disease $(1.43 \%)$, encephalitis $(1.14 \%)$, infective endocarditis (1.57\%) and stroke (1.29\%) (Table 7).

Table 7: Various pathologies encountered in the studied cases.

\begin{tabular}{|lll|}
\hline Pathologies in cases & No. of patients & $\%$ \\
\hline Alcoholic liver disease & 11 & 1.57 \\
\hline Bilateral pneumonitis & 89 & 12.71 \\
\hline Chronic kidney disease & 10 & 1.43 \\
\hline COPD with respiratory failure & 73 & 10.43 \\
\hline Encephalitis & 8 & 1.14 \\
\hline Guillain Barre syndrome & 27 & 3.86 \\
\hline HELLP syndrome & 85 & 12.14 \\
\hline Infective endocarditis & 11 & 1.57 \\
\hline Lung abscess & 21 & 3.00 \\
\hline Meningitis & 43 & 6.14 \\
\hline Organophosphate poisoning & 174 & 24.86 \\
\hline Sepsis with MODS & 33 & 4.71 \\
\hline snake bite & 106 & 15.14 \\
\hline Stroke & 9 & 1.29 \\
\hline Total & 700 & 100 \\
\hline
\end{tabular}

All prescriptions were analyzed to know the individual antibiotics used in patients admitted in MICU.

The careful analysis of the prescriptions showed that the most common antibiotic used in MICU was ceftriaxone which was used in 226 patients $(21.42 \%)$. The other common antibiotics used were combination of piperacillin 
and tazobactam which was used in 127 (12.04\%) patients, metronidazole $(11.85 \%)$, combination of ceftazidime and sulbactam $(10.05 \%)$ and meropenem which was used in 94 $(8.91 \%)$ patients. Least commonly used antibiotics were cefotaxime $(0.95 \%)$, combination of cefoperazone and sulbactam $(1.04 \%)$, gentamicin $(1.04 \%)$ and clindamycin $(1.99 \%)$ (Table 8).

\section{Table 8: Individual antibiotics used in patients} admitted in MICU.

\begin{tabular}{|lll|}
\hline Antibiotics & Prescriptions & $\%$ \\
\hline Ceftriaxone & 226 & 21.42 \\
\hline Ceftazidime+sulbactam & 106 & 10.05 \\
\hline Cefotaxime & 10 & 0.95 \\
\hline Cefaperazone+sulbactam & 11 & 1.04 \\
\hline $\begin{array}{l}\text { Amoxicilline+potassium } \\
\text { clavulanate }\end{array}$ & 39 & 3.70 \\
\hline Piperacilline+tazobactum & 127 & 12.04 \\
\hline Amikacin & 50 & 4.74 \\
\hline Azithromycin & 34 & 3.22 \\
\hline Clindamycin & 21 & 1.99 \\
\hline Colistin & 33 & 3.13 \\
\hline Gentamicin & 11 & 1.04 \\
\hline Levofloxacin & 32 & 3.03 \\
\hline Linezolid & 74 & 7.01 \\
\hline Metronidazole & 125 & 11.85 \\
\hline Vacomycin & 62 & 5.88 \\
\hline Meropenem & 94 & 8.91 \\
\hline Total & 1055 & 100 \\
\hline
\end{tabular}

Table 9: Class of antibiotics used in patients admitted in MICU.

\begin{tabular}{|lll|}
\hline Antibiotics & Prescriptions & $\%$ \\
\hline Cephalosporins & 353 & 33.46 \\
\hline Penicillins & 166 & 15.73 \\
\hline Aminoglycosides & 61 & 5.78 \\
\hline Glycopeptides & 62 & 5.88 \\
\hline Macrolides & 34 & 3.22 \\
\hline Lincosamides & 21 & 1.99 \\
\hline Oxazolidinones & 74 & 7.01 \\
\hline Quinolones & 32 & 3.03 \\
\hline Polymyxins & 33 & 3.13 \\
\hline Nitroimidazole & 125 & 11.85 \\
\hline Carbapenems & 94 & 8.91 \\
\hline Total & 1055 & 100 \\
\hline
\end{tabular}

All prescriptions were analyzed to know the class of antibiotics used in patients admitted in MICU.

Out of 1055 prescriptions, most common class of antibiotics used was cephalosporins $(33.46 \%)$ followed by penicillins $(15.73 \%)$, nitroimidazole $(11.85 \%)$ and carbapenems $(8.91 \%)$. Least commonly prescribed class of antibiotics were lincosamides (1.99\%), quinolones (3.03\%) and polymyxins $(3.13 \%$ ) (Table 9 ).
Combination of Ceftazidime and sulbactam was used in snake bite cases. All patients of meningitis received ceftriaxone and vancomycin. Only 2 patients of meningitis were given meropenem on the basis of culture sensitivity reports. All patients with chronic kidney disease received cefotaxime. Cefoperazone and sulbactam combination was given in 11 patients with alcoholic liver disease. Amoxycillin and potassium clavulanate combination was used in patients with COPD and respiratory failure whereas combination of piperacilline and tazobactam was used in bilateral pneumonia and patients with HELLP syndrome. Amikacin was given in patients with bilateral pneumonia as well as encephalitis whereas gentamicin was given in patients with infective endocarditis. Macrolide antibiotic azithromycin was given in 34 patients with COPD with respiratory failure. Patients diagnosed to be having lung abscess was treated by clindamycin. Colistin and levofloxacin was given in 33 and 32 patients with sepsis with multiorgan dysfunction. Metronidazole was given in 105 patients with snake bite and 11 patients with alcoholic liver disease. Meropenem was used in patients with bilateral pneumonia, GBS and lung abscess (Table 10).

The analysis of the patients on the basis of whether they received monotherapy or combination therapy showed that out of 700 patients $217(31 \%)$ patients received monotherapy whereas remaining $483(69 \%)$ patients received some or the other form of combination therapy. Generally, patients with chronic kidney diseases, stroke and organophosphorus poisoning received monotherapy and rest of the patients were give combination of different classes of antibiotics (Table 11).

The drugs used in monotherapy were ceftriaxone (24.86) followed by azithromycin $(4.71 \%)$ and cefotaxime $(1.43 \%)$. Overall $217 \quad(31 \%)$ patients received monotherapy. Monotherapy was given mainly in patients with chronic kidney diseases, stroke and organophosphorus poisoning (Table 12).

The most common combination of the drugs used was Ceftazidime+sulbactam along with metronidazole which was used in $106(15.14 \%)$ patients with snake bite. The other common combination of antibiotics used was piperacilline and tazobactam which was used in 85 $(12.14 \%)$ patients of HELLP syndrome. Combination of meropenem and linezolid was used in $74(10.57 \%)$ patients whereas piperacilline+tazobactum and amikacin was used $42(6 \%)$ patients with bilateral pneumonia. Least commonly used combinations were ceftriaxone and metronidazole which was used in $9(1.29 \%)$ patients whereas vancomycin and gentamicin was used in 11 $(1.57 \%)$ patients (Table 13 ).

Finally, the prescriptions were analyzed for the duration of the treatment.

Patients with alcoholic liver diseases, chronic kidney diseases, COPD with respiratory failure, encephalitis, infective endocarditis, lung abscess, meningitis, sepsis and 
stroke were treated for 14 days whereas patients with bilateral pneumonitis, HELLP syndrome, OP poisoning and snake bite were treated for a mean duration of 7 days (Table 14).

Table 10: Type of antibiotics in different clinical conditions.

\begin{tabular}{|c|c|c|c|c|c|c|c|c|c|c|c|c|c|c|c|}
\hline $\begin{array}{l}\text { Anti- } \\
\text { biotics } \\
\text { prescribed }\end{array}$ & $\begin{array}{l}\text { Alcohol } \\
\text { liver } \\
\text { disease }\end{array}$ & $\begin{array}{l}\text { Bilateral } \\
\text { pneu- } \\
\text { monitis }\end{array}$ & $\begin{array}{l}\text { Chronic } \\
\text { kidney } \\
\text { disease }\end{array}$ & $\begin{array}{l}\text { COPD with } \\
\text { Respiratory } \\
\text { failure }\end{array}$ & $\begin{array}{l}\text { Ence- } \\
\text { phalitis }\end{array}$ & GBS & $\begin{array}{l}\text { HELLP } \\
\text { Syndro- } \\
\text { me }\end{array}$ & $\begin{array}{l}\text { Infective } \\
\text { Endo- } \\
\text { carditis }\end{array}$ & $\begin{array}{l}\text { Lung } \\
\text { abscess }\end{array}$ & $\begin{array}{l}\text { Meni- } \\
\text { ngitis }\end{array}$ & $\begin{array}{l}\text { OP } \\
\text { pois- } \\
\text { oning }\end{array}$ & $\begin{array}{l}\text { Sepsis } \\
\text { with } \\
\text { MODS }\end{array}$ & $\begin{array}{l}\text { Snake } \\
\text { bite }\end{array}$ & Stroke & Total \\
\hline $\begin{array}{l}\text { Ceftazidime } \\
\text { +sulbactam }\end{array}$ & - & - & - & - & - & - & - & - & - & - & - & - & 106 & - & 106 \\
\hline Ceftriaxone & - & - & - & - & - & - & - & - & - & 43 & 174 & - & - & 9 & 226 \\
\hline Cefotaxime & - & - & 10 & - & - & - & - & - & - & - & - & - & - & - & 10 \\
\hline $\begin{array}{l}\text { Cefaperazone } \\
+ \text { sulbactam }\end{array}$ & 11 & - & - & - & - & - & - & - & - & - & - & - & - & - & 11 \\
\hline $\begin{array}{l}\text { Amoxicilline } \\
\text { +potassium } \\
\text { clavulanate }\end{array}$ & - & - & - & 39 & - & - & - & - & - & - & - & - & - & - & 39 \\
\hline $\begin{array}{l}\text { Piperacilline+ } \\
\text { tazobactum }\end{array}$ & - & 42 & - & - & - & - & 85 & - & - & - & - & - & - & - & 127 \\
\hline Amikacin & - & 42 & - & - & 8 & - & - & - & - & - & - & - & - & - & 50 \\
\hline Azithromycin & - & - & - & 34 & - & - & - & - & - & - & - & - & - & - & 34 \\
\hline Clindamycin & - & - & - & - & - & - & - & - & 21 & - & - & - & - & - & 21 \\
\hline Colistin & - & - & - & - & - & - & - & - & - & - & - & 33 & - & - & 33 \\
\hline Gentamicin & - & - & - & - & - & - & - & 11 & - & - & - & - & - & - & 11 \\
\hline Levofloxacin & - & - & - & - & - & - & - & - & - & - & - & 32 & - & - & 32 \\
\hline Linezolid & - & 47 & - & - & - & 26 & - & - & - & - & - & - & 1 & - & 74 \\
\hline Metronidazole & 11 & - & - & - & - & - & - & - & - & - & - & - & 105 & 9 & 125 \\
\hline Vancomycin & - & - & - & - & 8 & - & - & 11 & - & 43 & - & - & - & - & 62 \\
\hline Meropenem & 3 & 12 & - & 15 & - & 2 & 12 & 1 & 2 & 2 & 25 & 1 & 18 & - & 94 \\
\hline
\end{tabular}

Table 11: Monotherapy vs combination therapy in the studied cases.

\begin{tabular}{|lll|}
\hline $\begin{array}{l}\text { Monotherapy vs combination } \\
\text { therapy }\end{array}$ & No. of cases & $\%$ \\
\hline Monotherapy & 217 & 31 \\
\hline Combination therapy & 483 & 69 \\
\hline Total & 700 & 100 \\
\hline
\end{tabular}

Table 12: Monotherapy in studied cases.

\begin{tabular}{|lll|}
\hline Antibiotic & No. of cases & $\%$ \\
\hline Ceftriaxone & 174 & 24.86 \\
\hline Azithromycin & 33 & 4.71 \\
\hline Cefotaxime & 10 & 1.43 \\
\hline Total & 217 & 31 \\
\hline
\end{tabular}

Table 13: Combinations of antibiotics in studied cases.

\begin{tabular}{|lll|}
\hline Combinations of antibiotics & Number of cases & Percentage \\
\hline Piperacilline+tazobactum+amikacin & 42 & $6.00 \%$ \\
\hline Cefaperazone+sulbactam+metronidazole & 11 & $1.57 \%$ \\
\hline Meropenem+linezolid & 74 & $10.57 \%$ \\
\hline Amoxycilline+potassium cluvalunate & 40 & $5.71 \%$ \\
\hline Vancomycin+amikacin & 8 & $1.14 \%$ \\
\hline Piperacilline+tazobactum & 85 & $12.14 \%$ \\
\hline Vancomycin+gentamycin & 11 & $1.57 \%$ \\
\hline Meropenem+clindamycin & 21 & $3.00 \%$ \\
\hline Ceftriaxone+vancomycin & 43 & $6.14 \%$ \\
\hline Colistin+levofloxacin & 33 & $4.71 \%$ \\
\hline Ceftazidime+sulbactam+metronidazole & 106 & $15.14 \%$ \\
\hline Ceftriaxone+metronidazole & 9 & $1.29 \%$ \\
\hline Total & 483 & $69 \%$ \\
\hline
\end{tabular}


Table 14: Mean duration of the treatment in studied cases.

\begin{tabular}{|lll|}
\hline Pathologies & $\begin{array}{l}\text { No. of } \\
\text { patients }\end{array}$ & $\begin{array}{l}\text { Mean duration } \\
\text { of treatment } \\
\text { (days) }\end{array}$ \\
\hline Alcoholic liver disease & 11 & 14 \\
\hline Bilateral pneumonitis & 89 & 7 \\
\hline Chronic kidney disease & 10 & 14 \\
\hline $\begin{array}{l}\text { COPD with respiratory } \\
\text { failure }\end{array}$ & 73 & 14 \\
\hline Encephalitis & 8 & 14 \\
\hline Guillain Barre syndrome & 27 & 14 \\
\hline HELLP syndrome & 85 & 7 \\
\hline Infective endocarditis & 11 & 14 \\
\hline Lung abscess & 21 & 14 \\
\hline Meningitis & 43 & 14 \\
\hline $\begin{array}{l}\text { Organophosphate } \\
\text { poisoning }\end{array}$ & 174 & 7 \\
\hline Sepsis with MODS & 33 & 14 \\
\hline Snake bite & 106 & 7 \\
\hline Stroke & 9 & 14 \\
\hline
\end{tabular}

\section{DISCUSSION}

The study was undertaken with an aim to analyse the prescription pattern of antibiotics in MICU. The prescription data of all patients at admission into the MICU was noted with regards to antibiotic prescription and the class of antibiotics. The antibiotics prescription pattern was analyzed till the Patient was discharged from Medicine ICU.

In this study, prescriptions of a total of 700 patients aged 18 years and above admitted to intensive care unit were reviewed. The overall antibiotic use was $70.85 \%$. Around $29.15 \%$ did not receive antibiotics. The antibiotics were not only used for treatment of infection but also for prevention of secondary infections following invasive procedures. In comparison with this study observations, lesser use of antibiotics was found in the similar studies carried out by Curcio D (51\%), Radji M et al (53.32\%), and Johnston D et al, $(55.2 \%)^{7-9}$

Data analysis of gender distribution in present study showed that there was a male predominance in this study. Out of 700 studied cases there were 423 males and 277 females with a M:F ratio of 1:0.65. Similar male preponderance was showed in studies carried out by Williams A et al, (males-131, females-69 and M:F-1:0.52), Anand $\mathrm{N}$ et al, (males-717, females-359 and M:F-1:0.50) and Perveen RA et al (males-115, females-101 and M:F1:0.87). ${ }^{10-12}$ The difference between gender distribution was due to differences in admissions in MICU.

The analysis of mean age of the studied cases in MICU showed that in this study the mean age of the cases was found to be $34.16 \pm 14.13$. In contrast, studies carried out by
Mangrulkar SV et al, showed mean age of $>60$ years $(62.2+/-16.24$ years). Mean age $>60$ years was also reported by Kara A et al, $(60.9 \pm 18.0$ years) and Mondal $\mathrm{K}$ et al, $\left(62.32 \pm 17.93\right.$ years) respectively. ${ }^{13-15}$ One of the important reasons for a younger mean age in this group appears to be due to the fact that many of the patients were admitted in ICU for organo-phosphorus poisoning and snake bite which were usually seen in younger and active males doing farming. The relatively high mean age in other studies was due to the fact that in those studies majority of the patients were admitted due to cardiac or pulmonary problems which is usually seen at a relatively older age.

In this study, the co-morbidities like diabetes, hypertension were seen in $38.86 \%$ patients. In comparison, higher incidence of co-morbidities was seen in studies carried out by Mondal $\mathrm{K}$ et al $(76.6 \%)$, Adrie $\mathrm{C}$ et al, (48.1\%) and Shallcross L et al, (45.7\%) respectively. The differences could be because of different patient populations. ${ }^{15-17}$

The analysis of indications for the admissions in MICU in this study showed that the most common disease for which patients were admitted in intensive care units included organophosphorus poisoning $(24.86 \%)$, snake bite $(15.14 \%)$, bilateral pneumonitis (12.71\%), HELLP syndrome $(12.14 \%)$, respectively and the least common pathologies included COPD with respiratory failure $(10.43 \%)$, meningitis $(6.14 \%)$, sepsis with MODS (4.71\%), GBS $(3.86 \%)$, lung abscess $(3.0 \%)$, alcoholic liver disease $(1.57 \%)$, chronic kidney disease $(1.43 \%)$, encephalitis $(1.14 \%)$, infective endocarditis $(1.57 \%)$ and stroke $(1.29 \%)$. In contrast, the most common indications for admission in MICU in study conducted by Crucio D was nosocomial pneumonia (21\%), community pneumonia $(14 \%)$, intra-abdominal infections $(12 \%)$, genitourinary infections (12\%), CNS infections $(6.7 \%)$, skin infection $(6.7 \%)$, sepsis $(6.7 \%)$, etc. ${ }^{7}$ Maharani B et al, reported most common cause of MICU admission to be infections $(22.5 \%)$, cardiac pathologies $(16.6 \%)$, hepatic pathologies (15.9\%), pulmonary disorders $(13.9 \%)$ electrolyte disorder (9.3\%), CNS disorders (7.9\%), chronic kidney disease $(7.3 \%)$, poisoning $(3.3 \%)$ respectively. ${ }^{18}$ Irrespective of the pathology for which patients are initially admitted there are higher chances of patients receiving antibiotics in MICU as compared to the patients who are managed in wards because of increased incidence of invasive procedures like central lines, intubation, etc. in patients admitted in MICU.

The most common single antibiotic used in the studied cases was found to be third generation cephalosporin ceftriaxone which was given in $21.42 \%$ patients. The other common antibiotics (either alone or in combination) administered was found to be combination of piperacillin and tazobactam which was used in 127 (12.04\%) patients, metronidazole $(11.85 \%)$, combination of ceftazidime and sulbactam $(10.05 \%)$ and meropenem which was used in 94 $(8.91 \%)$ patients. cefotaxime combination of cefoperazone and sulbactam gentamicin and clindamycin was used in $0.95 \%, 1.04 \%, 1.04 \%$ and $1.99 \%$ patients respectively. In 
comparison, Malacarne $\mathrm{P}$ et al, showed that the single different trends of antibiotic use; vancomycin (30.1\%), ceftazidime $(26.6 \%)$, ciprofloxacin $(25.9 \%)$ and gentamicin (25.2\%). ${ }^{19}$ Another study by Maharani B et al, showed yet another antibiotic usage pattern cefotaxime (37.6\%), metronidazole (19.9\%), azithromycin (17.2\%), combination of piperacilline and tazobactum (12.2\%) to be the common antibiotics used in MICU settings. ${ }^{18}$ These differences may be of different protocols followed by the MICU setups, admission patterns and comorbidities associated, availability of antibiotics as per the resources, resistance patterns reported in particular hospitals, and other reasons, etc.

The analysis of patients on the basis of whether they received monotherapy or combination therapy showed that $217(31 \%)$ patients received monotherapy whereas remaining $483(69 \%)$ patients received some or the other form of combination therapy. The patients with chronic kidney diseases were mostly used by monotherapy whereas the patients with sepsis, invasive procedures and HELLP syndrome were mostly treated by combination therapy. Similarly, studies dealing with the subject of antibiotic used in MICU showed that majority of the patients with combinations of antibiotics as compared to monotherapy: Ahmed A et al, reported that combination therapy was given in $53 \%$ cases. $^{20}$ In another study, conducted by Chokshi $\mathrm{R}$ et al, reported that combinations of antibiotics was very common $61 \%$ cases. $^{21}$

The analysis of prescription with monotherapy showed that ceftriaxone (24.86) followed by azithromycin $(4.71 \%)$ and cefotaxime $(1.43 \%)$ was the most common single antibiotic used. Overall 217 (31\%) patients received monotherapy. Similar studies conducted by Erbay E et al, showed that the most common monotherapy was given by ceftriaxone $(15.2 \%)$ followed by aminoglycoside $(12.1 \%) .^{22}$ In another study conducted by Maharani et al, showed that the most common single antibiotic used in MICU was cefotaxime $(37.6 \%)$ followed by metronidazole $(19.9 \%)$ and azithromycin $(17.2 \%) .{ }^{18}$ In all the studies, it was found that the cephalosporins were the most common single antibiotic used. These differences may due to difference patient admitted, organisms involved in indications, prophylactic indications, resistance patterns reported in particular hospital, etc.

The use of combination of the antibiotics in this study showed that, ceftazidime+sulbactam along with metronidazole was used in $106(15.14 \%)$ patients with snake bite. Piperacilline+tazobactam was used in 85 $(12.14 \%)$ patients of HELLP syndrome. Combination of meropenem+linezolid was used in $74(10.57 \%)$ patients whereas piperacilline+tazobactum and amikacin was used $42(6 \%)$ patients with bilateral pneumonia. As compared to this results, study carried out by Johnston D et al, showed most common use of amoxicillin+clacvulinic (22.4\%) followed by piperacilline+tazobactam (15.68), ceftazizdime+sulbactam (13.72\%). ${ }^{9}$ Another study carried out by Maharani B, et al, showed most common combination used amoxicillin+clacvulinic (42.7\%), piperacilline+tazobactam $(12.8 \%)$ and amoxicillin+ benzylpenicillin $(44.2 \%)$ respectively. ${ }^{18}$ The different pattern of antibiotics usage reflected showed the usage trends in different setup. This may also be related to protocols of usages followed, indications and susceptible microorganisms being treated, prophylactic indications, etc.

Mean duration of antibiotic therapy was finally analyzed. In this study, the mean duration of antibiotic therapy was found to be $11.83 \pm 3.25$ days which included the analysis of all patients admitted and receiving antibiotics for either 7 or 14 days. In general, the studies conducted by Durgad $\mathrm{AG}$ et al, and Zilahi $\mathrm{G}$ et al, reported mean duration of 10 days of antibiotic therapy. ${ }^{23,24}$

\section{CONCLUSION}

Out of the total 988 patients admitted in MICU, 700 patients received systemic antibiotics bringing the incidence of systemic antibiotics use in the intensive care units to be $70.85 \%$. Irrespective of the pathology for which patients are initially admitted there are higher chances of patients receiving antibiotics in MICU as compared to the patients who are managed in wards because of increased incidence of invasive procedures in patients admitted in MICU. The differences in the use of antibiotics, mono or combination therapy with antibiotics usage is definitely related to antibiotic usage protocols and antibiotic policies at an institute or hospitals across. Additionally, this will also depend on admission cases in MICU and comorbidities associated. A huge impact of antibiotic usage will also depend on availability of antibiotics, resources, current trends in resistance patterns, hospital infections, etc. Author concluded in the present study that, all patients admitted in this tertiary care hospital received antibiotics as per the protocols of the hospital and was found to be rational.

\section{ACKNOWLEDGEMENTS}

Authors would like to thank Department of Medicine, Government Medical College, Aurangabad, Maharashtra, India and Dr. Hrushikesh Khadilkar, Associate professor, PSM, for their support during study.

Funding: No funding sources

Conflict of interest: None declared

Ethical approval: The study was approved by the Institutional Ethics Committee of Government Medical College, Aurangabad, Maharashtra, India

\section{REFERENCES}

1. Mittal N, Mittal R, Singh I, Shafiq N, Malhotra S. Drug utilization study in a tertiary care center: recommendations for improving hospital drug dispensing policies. Ind $\mathbf{J}$ Pharmaceut Sci. 2014;76(4):308. 
2. Gould IM, Bal AM. New antibiotic agents in the pipeline and how they can help overcome microbial resistance. Virulence. 2013;4(2):185-91.

3. Chant C, Leung A, Friedrich JO. Optimal dosing of antibiotics in critically ill patients by using continuous/extended infusions: a systematic review and meta-analysis. Crit Care. 2013;17(6):R279.

4. Murray MJ, Coursin DB. Multiple organ dysfunction syndrome. Yale J Biol Med. 1993;66(5):501.

5. Roca I, Akova M, Baquero F, Carlet J, Cavaleri M, Coenen S, et al. The global threat of antimicrobial resistance: science for intervention. New Microbes New Inf. 2015;6:22-9.

6. Lighthall GK, Vazquez-Guillamet C. Understanding decision making in critical care. Clin Med Res. 2015;13(3-4):156-68.

7. Curcio D. Latin American antibiotic use in intensive care unit group. antibiotic prescriptions in critically-ill patients: a Latin American experience. Ann Med Heal Sci Res. 2013;3(2):220.

8. Radji M, Fauziah S, Aribinuko N. Antibiotic sensitivity pattern of bacterial pathogens in the intensive care unit of Fatmawati Hospital, Indonesia. Asian Pacific J Trop Biomed. 2011;1(1):39-42.

9. Johnston D, Khan R, Miot J, Moch S, Deventer Y, Richards G. Usage of antibiotics in the intensive care units of an academic tertiary-level hospital. Southern Afr J Inf Dis. 2018;33(4):106-13.

10. Williams A, Mathai AS, Phillips AS. Antibiotic prescription patterns at admission into a tertiary level intensive care unit in Northern India. J Pharmacy Bioallied Sci. 2011;3(4):531

11. Anand N, Nayak IN, Advaitha MV, Thaikattil NJ, Kantanavar KA, Anand S. Antimicrobial agent's utilization and cost pattern in an Intensive Care Unit of a Teaching Hospital in South India. Ind J Crit Care Med Peer-Rev Off Pub Ind Soc Crit Care Med. 2016;20(5):274.

12. Perveen RA, Nasir M, Farha N, Islam MA. Antibiotics in ICU: the challenges of use, cost and response in a tertiary care hospital. Inter J Med Res Heal Sci. 2018;7(6):94-9.

13. Mangrulkar SV, Mangrulkar S, Khair P, Phalke A. Antibiotic use in the intensive care unit. JAPI. 2012;60:15.

14. Kara A, Sahar I, Güllü MN, Süner KÖ, Rollas K, Halacli B, et al. The characteristics of antibiotic use and changing patterns in an intensive care unit. Dah Cerr Bilim Yog Bak Derg. 2016;7(2):53.
15. Mondal K, Biswas S, Ghosh A, Dalui SK, Datta A, Biswas S. Rationality of utilization of antimicrobial agents in medical intensive care unit of a tertiary care hospital. Int J Basic Clin Pharmacol. 2016;5:2168-73.

16. Adrie C, Schwebel C, Garrouste-Orgeas M, Vignoud L, Planquette B, Azoulay E, et al. Initial use of one or two antibiotics for critically ill patients with community-acquired pneumonia: impact on survival and bacterial resistance. Crit Care. 2013;17(6):R265.

17. Shallcross L, Beckley N, Rait G, Hayward A, Petersen I. Antibiotic prescribing frequency amongst patients in primary care: a cohort study using electronic health records. J Antimicrob Chemotherapy. 2017;72(6):1818-24.

18. Maharani B, LourduJafrin A, Prakash M., Priyadarshini P. Prescription pattern of patients admitted in the intensive care unit of a tertiary care hospital in Puducherry, India: a cross sectional study Inter J Basic Clin Pharmacol. 2017;6(12):2823.

19. Malacarne P, Rossi C, Bertolini G. Antibiotic usage in intensive care units: a pharmaco-epidemiological multicentre study. J Antimicrob Chemotherapy. 2004;54(1):221-4.

20. Ahmed A, Azim A, Gurjar M, Baronia AK. Current concepts in combination antibiotic therapy for critically ill patients. Ind J Crit Care Med Peer-Rev Off Pub Ind Soc Crit Care Med. 2014;18(5):310.

21. Chokshi R, Restrepo MI, Weeratunge N, Frei CR, Anzueto A, Mortensen EM. Monotherapy versus combination antibiotic therapy for patients with bacteremic Streptococcus pneumoniae communityacquired pneumonia. Euro J Clin Microbiol Inf Dis. 2007;26(7):447-51.

22. Erbay A, Bodur H, Akıncı E, Colpan A. Evaluation of antibiotic use in intensive care units of a tertiary care hospital in Turkey. J Hosp inf. 2005;59(1):53-61.

23. Durgad AG, Varadarajan S. Prevalence of NI in the intensive care unit .Int J Res Med Sci 2015;3:3514-8.

24. Zilahi G, McMahon MA, Povoa P, Martin-Loeches I. Duration of antibiotic therapy in the intensive care unit. J Thoracic Dis. 2016;8(12):3774.

Cite this article as: Naikwadi IB, Baig MS,

Bhattacharya M. To study the prescription pattern of antibiotics in medicine intensive care unit at tertiary care hospital. Int J Basic Clin Pharmacol 2019;8:73845 . 